\title{
REPARACIÓN INTEGRAL: PRINCIPIOS APLICABLES Y MODALIDADES DE REPARACIÓN
}

INTEGRAL REPAIR: APPLICABLE PRINCIPLES AND REPAIR MODALITIES

\author{
Glenda Anabel Granda Torres* \\ Carmen del Cisne Herrera Abrahan ${ }^{* *}$
}

Resumen: El objetivo de la presente investigación es analizar la reparación integral, los principios sobre los que se basa y los modelos de reparación integral. Los modelos de reparación pueden aplicarse en un mismo caso, por ello es necesario la evaluación del daño ocasionado para aplicar un tipo de reparación específica en la que puede concurrir la restitución, indemnización, rehabilitación, medidas de satisfacción y garantías de no repetición. La metodología que se utilizó es el método analítico sintético. El artículo consta de cuatro secciones. La primera sección desarrolla la introducción del trabajo de investigación. La segunda sección se analiza la reparación integral, su acceso y consulta a las víctimas de las reparaciones, los beneficiarios de las reparaciones, las reparaciones proporcionales adecuadas, causalidad; y, estándar y carga de la prueba. En la tercera sección se estudia los principios sobre los que se basan las reparaciones. En la cuarta sección se desarrolla los modelos de reparación integral, entre ellos la reparación individual que abarca la restitución, la

\footnotetext{
* Abogada por la Universidad Nacional de Loja (Ecuador). Magíster en Derecho Procesal por la Universidad Católica de Santiago de Guayaquil (Ecuador). Doctorando en Derecho por la Universidad Nacional Mar del Plata (Argentina). Litigante en materias Constitucionales, Penales y Civiles. Asesora de la Fundación Agua Clara. https://orcid.org/0000-0003-3173-726X glendagranda30@gmail.com

** Agente Fiscal de Loja. Docente de la Universidad Técnica Particular de Loja (Ecuador). Maestría en Ciencias Penales y Especialista en Derecho Procesal Penal por la misma institución. Cursa el programa de doctorado en Ciencias Jurídicas en la Universidad de Buenos Aires (Argentina). https://orcid.org/0000-0001-5909-2948 ccisneh@ gmail.com
} 
indemnización monetaria y rehabilitación; y, en la reparación colectiva, se estudian las medidas de satisfacción y garantías de no repetición y se concluye que la reparación integral es un derecho de las víctimas reconocido en el derecho internacional por lo que se reconocen varios principios aplicables al momento de dictar una reparación, además existen dos modalidades para reparar integralmente a la víctima una que es la individual y otra que es la colectiva.

Palabras clave: Reparación integral, principios, modalidades de reparación, víctimas, derechos humanos

Abstract: The objective of the present investigation is to analyze the integral repair, the principles on which it is based and the models of integral repair. The models of reparation can be applied in the same case, for this reason the evaluation of the damage caused is necessary to apply a specific type of reparation in which restitution, compensation, rehabilitation, satisfaction measures and guarantees of non-repetition may concur. The methodology used is the synthetic analytical method. The article consists of four sections. The first section develops the introduction of the research work. The second section analyzes comprehensive reparation, its access and consultation with victims of reparations, beneficiaries of reparations, adequate proportional reparations, causality; and, standard and burden of proof. The third section examines the principles on which reparations are based. In the fourth section the models of integral reparation are developed, among them the individual reparation that includes restitution, monetary compensation and rehabilitation; and, in the collective reparation, measures of satisfaction and guarantees of non-repetition are studied and it is concluded that comprehensive reparation is a right of the victims recognized in international law, therefore several principles applicable at the time of issuing reparation are recognized. In addition, there are two ways to fully repair the victim, one that is individual and the other that is collective.

Keywords: Comprehensive Reparation, Principles, Reparation Modalities, Victims, Human Rights

Sumario. I. Introducción. II. Reparación integral. II.1. Acceso y consulta a las víctimas de las reparaciones. II.2. Beneficiarios de las reparaciones. II.3. Reparaciones proporcionales y adecuadas. II.4. Causalidad. II.5. Estándar y carga de la prueba. III. Principios sobre los que se basan las reparaciones. IV. Modelos de reparación integral. IV.1. Reparación individual. a) Restitución. b) Indemnización monetaria. c) Rehabilitación. IV.2. Reparación colectiva. a) 
Medidas de satisfacción. b) Garantías de no repetición. V. Conclusiones. Referencias.

\section{INTRODUCCIÓN}

La reparación integral ha sido reconocida internacionalmente a través de los principios relativos por la Corte Penal Internacional, y por los principios derivados del derecho internacional de los derechos humanos, como los principios básicos de la ONU, Principios para las Víctimas, Conjunto de Principios para la Protección de todas las Personas Sometidas a Cualquier forma de Detención o Prisión, Convención Americana de Derechos Humanos, Convención contra la Tortura y Otros Tratos o Penas Crueles, Inhumanos o Degradantes, Convención Interamericana para Prevenir y Sancionar la Tortura; y, Convención Internacional para la Protección de Todas las Personas contra las Desapariciones Forzadas, incluyendo los desarrollados por la jurisprudencia de tribunales transnacionales de derechos humanos.

En este trabajo de investigación, se revisarán los principios aplicables a las reparaciones cuando son dictadas en procesos judiciales, y las modalidades de reparación individual y colectiva que han sido desarrolladas por los órganos de protección de los derechos. Se cita algunas jurisprudencias de la Corte Interamericana de Derechos Humanos (en adelante $\mathrm{CIDH}$ ) y de la Corte Constitucional del Ecuador en las que se desarrollan las medidas de reparación integral de las víctimas.

\section{REPARACIÓN INTEGRAL}

La reparación integral comprende modalidades individuales de reparación a través de indemnizaciones monetarias, restitución y rehabilitación, así como modalidades de reparación colectiva que incluyen medidas de satisfacción y garantías de no repetición, sin perjuicio de otras modalidades de reparación reconocidas por los órganos internacionales de protección de derechos humanos.

En ese contexto, la reparación integral es un derecho que busca reducir el alcance de los daños, pérdidas y perjuicios ocasionados a las víctimas, y a las necesidades individuales y colectivas de éstas, con especial consideración de los grupos vulnerables (Benavides \& Escudero, 2013).

La reparación integral de las víctimas proviene del derecho internacional, a través del derecho penal internacional según el cual merecen reparación las víctimas de crímenes de lesa humanidad —especialmente en 
las sentencias de los tribunales penales luego de la segunda guerra mundial. La cobertura de este derecho se fue expandiendo hacia los sistemas de protección de derechos humanos. Es por ello, que el desarrollo más significativo del derecho a la reparación lo encontramos en la jurisprudencia de la CIDH.

Asimismo, en Ecuador se ha reconocido constitucionalmente el derecho a la reparación integral para comunas, comunidades, pueblos y nacionalidades indígenas (Constitución, art. 57), y en el caso de infracciones penales a la víctima se garantiza que gocen de protección especial, mediante mecanismos para una reparación integral (Constitución, art. 78). Incluso se ha reconocido este derecho como un fin del proceso penal que es la reparación del daño causado a la víctima, quien puede participar como parte del proceso penal (Benavides \& Escudero, 2013; Constitución, art. 58). En este sentido, el Código Orgánico Integral Penal (2014) guarda armonía con la Constitución, y entre los derechos de las víctimas reconoce una reparación material e inmaterial, que señala la adopción de mecanismos para la reparación integral de los daños ocasionados que le permita a la víctima conocer de forma oportuna la verdad de los hechos, restablecer el derecho lesionado, la indemnización, la garantía de no repetición, y cualquier forma de reparación, relacionándose con el Art. 78 del citado cuerpo legal, en donde ya se define con precisión los Mecanismos de reparación integral, como las formas no excluyentes de reparación integral, sea individual o colectiva, orientada la reparación a restituir en la medida de lo posible al estado anterior de cuando se cometió la infracción, entonces, la reparación coadyuva a disminuir el daño ocasionado.

De igual manera, el reconocimiento de las garantías jurisdiccionales supone la obligación de los jueces, en caso de declararse la vulneración de derechos de ordenar la reparación integral por el daño material e inmaterial. La reparación integral procurará que la persona o personas titulares del derecho violado gocen y disfruten el derecho de la manera más adecuada posible y que se restablezca a la situación anterior a la violación. La reparación podrá incluir, entre otras formas, la restitución del derecho, la compensación económica o patrimonial, la rehabilitación, la satisfacción, las garantías de que el hecho no se repita, la obligación de remitir a la autoridad competente para investigar y sancionar, las medidas de reconocimiento, las disculpas públicas, la prestación de servicios públicos, la atención de salud. La reparación por el daño material comprenderá la compensación por la pérdida o detrimento de los ingresos de las personas afectadas, los gastos efectuados con motivo de los hechos y las consecuencias de carácter pecuniario que tengan un nexo causal con los hechos del caso. La reparación por el daño inmaterial comprenderá la compensación, mediante el pago de 
una cantidad de dinero o la entrega de bienes o servicios apreciables en dinero, por los sufrimientos y las aflicciones causadas a la persona afectada directa y a sus allegados, el menoscabo de valores muy significativos para las personas, así como las alteraciones, de carácter no pecuniario, en las condiciones de existencia del afectado o su familia. La reparación se realizará en función del tipo de violación, las circunstancias del caso, las consecuencias de los hechos y la afectación al proyecto de vida. En la sentencia o acuerdo reparatorio, deberá constar expresa mención de las obligaciones individualizadas, positivas y negativas, a cargo del destinatario de la decisión judicial y las circunstancias de tiempo, modo y lugar en que deben cumplirse, salvo la reparación económica que debe tramitarse de conformidad con el artículo siguiente. La persona titular o titulares del derecho violado deberán ser necesariamente escuchadas para determinar la reparación, de ser posible en la misma audiencia. Si la jueza o juez considera pertinente podrá convocar a nueva audiencia para tratar exclusivamente sobre la reparación, que deberá realizarse dentro del término de ocho días (Ley Orgánica de Garantías Jurisdiccionales y Control Constitucional, art. 18), se reconoce el derecho a la reparación y las modalidades de reparación desarrolladas por el derecho internacional de derechos humanos. No obstante, para la aplicación de las medidas de reparación es necesario considerar algunos principios generales.

La Corte Constitucional en el mismo sentido, ha manifestado que:

«(...) la reparación integral en el Ecuador, recoge no solo los parámetros de derechos humanos del ámbito internacional, sino que permite entender a la reparación como una directriz transversal en la estructura de la Constitución que se aplica no solo a los casos de violaciones 'graves' que responden a los estándares internacionales de gravedad - vinculadas a los 'delitos de discriminación o actos intolerantes dirigidos a colectivos, lesa humanidad y tortura o cualquier trato cruel o inhumano'- sino frente a la vulneración de cualquier derecho constitucional, que tiene que ser valorada, declarada y justificada por el operador de justicia constitucional, que conoce el caso concreto, para disponer la reparación pertinente» (Sentencia 009-14-SIS-CC).

\section{II.1. Acceso y consulta a las víctimas de las reparaciones}

Convine repasar la noción de víctima en la doctrina. Para Arroyo (2007, p. 117) la «víctima es el titular del bien jurídico penalmente protegido que ha sido dañado o puesto en peligro, es decir el sujeto pasivo». Por otro lado, Neuman (1984, p. 25) señala que la

«víctima es el que sufre el perjuicio. Es para la victimología, diríase clásica, al ser humano que padece daño en los bienes jurídicamente protegidos: vida, salud, 
propiedad, honor, honestidad, etc., por el hecho de otro e, incluso por accidentes debidos a factores humanos, mecánicos, como ocurre en los accidentes de trabajo».

Los órganos de protección de derechos deben escuchar las opiniones y observaciones de las víctimas y los familiares sobre los beneficios y prioridades con el fin de obtener una ayuda significativa para el proceso de reparaciones y los obstáculos que se les ha presentado para poder participar en dicho proceso.

Por ejemplo, en una sentencia de acción de protección se ordenó la reparación de una persona que había sido privado del derecho a la educación debido a su condición de persona con capacidades especiales. En la sentencia se anuló la libreta de calificaciones por considerarla sin motivación y discrecionalmente discriminatoria (Jueza de la Unidad Judicial de lo Civil y Mercantil del Cantón Loja, Acción de Protección 1333-201901645). En ese caso la acción de protección constituyó un recurso adecuado para reparar el daño. Por ello la Corte Constitucional ha manifestado que un recurso para ser idóneo y adecuado para reparar a las víctimas debe producir el efecto material de la reparación, caso contrario el recurso mismo es violatorio del derecho a la reparación integral (Corte Constitucional, sentencia constitucional 031-15-SIS-CC).

Incluso el derecho a la reparación se ve completamente garantizado:

«(...) con la aplicación íntegra de la sentencia o la reparación integral del derecho vulnerado; en otras palabras, gracias a esta garantía, los procesos constitucionales no llegan a su fin con la expedición de la sentencia, sino cuando haya cumplido con todos los actos que se haya dispuesto en ella y se ha llevado a cabo la reparación integral de los derechos vulnerados, tarea que además le corresponde a la Corte vigilar conforme sus atribuciones» (Sentencia 001-13-SIS$\mathrm{CC})$.

Por ello, el acceso de las víctimas a la reparación supone la posibilidad de que ellas pueden ejercitar la acción de incumplimiento de sentencias, para que, a través de ella se puedan efectuar la efectiva reparación.

\section{II.2. Beneficiarios de las reparaciones}

Las víctimas son las beneficiarias de las reparaciones. Entre ellas las víctimas directas e indirectas. Asimismo, las reparaciones colectivas al tener un efecto predominantemente simbólico, benefician a la comunidad en su conjunto. Es necesario reconocer que en cada caso las reparaciones pueden variar, así, por ejemplo, no pueden coincidir en un solo caso todas las medidas de reparación. 
Las victimas indirectas pueden ser los familiares de las víctimas directas que al existir una estrecha relación personal con las victimas sufrieron daños permanentes, que perdurarán hasta que no se conozca la verdad sobre las víctimas directas.

Las víctimas indirectas son aquellas que, por su relación con las víctimas directas, sufren daño, pérdida o perjuicio como consecuencia del daño sufrido por las víctimas directas. Como consecuencia de los hechos sufren graves daños psicológicos y cambios en su estado de ánimo, esto incluye entre otras secuelas, depresiones, ansiedad, y aislamiento social.

La intranquilidad asociada a la apremiante necesidad de conocer la verdad en procesos judiciales crea una situación de incertidumbre, que genera profundos trastornos en su vida. Esto es más grave para las víctimas indirectas si se considera la inoperancia y falta de independencia de los órganos encargados de investigar las violaciones a los derechos humanos y sancionar a los responsables. Por ello las víctimas indirectas reivindican su derecho a la verdad y a la justicia cuando intervienen en los procesos judiciales y se les reconoce medidas de reparación específicas.

\section{II.3. Reparaciones proporcionales y adecuadas}

Las víctimas deben recibir reparaciones apropiadas y adecuadas, de acuerdo con los daños que sufrieron. Igualmente, las reparaciones deben implementarse con celeridad, sin discriminación de género, edad, raza, color, idioma, religión o credo, opinión política o de otra índole, origen nacional, étnico o social, posición económica, nacimiento u otra condición. Esto sin perjuicio de las necesarias medidas afirmativas en favor de las personas más vulnerables.

Incluso la reparación surte efecto cuando no solamente se ha emitido la sentencia declaratoria de vulneración de derechos, sino que surte efecto cuando se han reparado efectivamente los daños ocasionados (Corte Constitucional sentencia constitucional 031- 15-SIS-CC).

\section{II.4. Causalidad}

La relación de causalidad existente entre los daños sufridos y las vulneraciones a los derechos, son dos requisitos importantes para que la persona tenga la condición de víctima. Las vulneraciones constituyen "la causa inmediata" de los daños por los que se solicita reparaciones.

Por ello, es necesario conocer quién es el vulnerador de los derechos, pues sobre ese recaerá la obligación de reparar los daños. En algunos casos las demandas de reparación son contra el Estado, en otros casos contra particulares. No obstante, en los procesos de exigibilidad de reparaciones 
debe demostrarse el vínculo que existe entre el daño, la vulneración de derechos y el obligado a reparar.

\section{II.5. Estándar y carga de la prueba}

Respecto de los hechos que son relevantes para la decisión que deberá otorgar reparaciones, se debe considerar que la «ponderación de probabilidades» es suficiente y proporcionada para calificar tales hechos, máxime si se considera la dificultad «que tienen las víctimas para obtener pruebas justificativas de su reclamación debido a la destrucción o indisponibilidad de las mismas» (Corte Penal Internacional, 01/04-01/062904, $2012 \S 253)$.

Imponer condiciones gravosas para la prueba de los daños y la determinación de las necesidades de las víctimas, implicaría una interpretación restrictiva del derecho a una reparación integral, adecuada y oportuna, conforme a los estándares internacionales en la materia (ONU, Principio 10).

\section{PRINCIPIOS SOBRE LOS QUE SE BASAN LAS REPARACIONES}

Una reparación adecuada, efectiva y rápida tiene por finalidad promover la justicia, remediando las violaciones manifiestas de las normas internacionales de derechos humanos o las violaciones graves del derecho internacional humanitario. La reparación ha de ser proporcional a la gravedad de las violaciones y al daño sufrido. Conforme a su derecho interno y a sus obligaciones jurídicas internacionales, los Estados concederán reparación a las víctimas por las acciones u omisiones que puedan atribuirse al Estado y constituyan violaciones manifiestas de las normas internacionales de derechos humanos o violaciones graves del derecho internacional humanitario (Resolución 60/147 de 16 de diciembre de 2005).

Los estados tienen la obligación de respetar, asegurar que se respeten $\mathrm{y}$ aplicar las normas internacionales de derechos humanos y el derecho internacional humanitario según lo previsto en los respectivos ordenamientos jurídicos (cfr. Resolución 60/147 de 16 de diciembre de 2005, Art.1).

La reparación integral se relaciona con otros derechos reconocidos en los instrumentos internacionales de protección de derechos humanos. Con el fin de satisfacer los principios de dignidad, no discriminación y no estigmatización, se debe otorgar un tratamiento justo e igualitario a las víctimas de violaciones de derechos humanos. 
Ello supone tomar en cuenta las necesidades de todas las víctimas. Las víctimas indirectas, también deben ser calificadas como vulnerables, en particular las niñas y niños que deben padecer los efectos que implican en su desarrollo vital, esto además si se considera que los niños, niñas y adolescentes en el Ecuador son un grupo de atención prioritaria, conforme al Art. 35 de la Constitución de la República del Ecuador.

Además, deben seguirse los principios de aplicación de los derechos previstos en el artículo 11 de la Constitución de la Republica del Ecuador, que entre otros establece la obligación del Estado de garantizar los derechos en orden al principio de igualdad y no discriminación. Es decir, que no se puede restringir el derecho a la reparación en base a las categorías sospechosas.

Así también en el Cuadernillo de Jurisprudencia de la Corte Interamericana de Derechos Humanos $\left(2019, \mathrm{n}^{\circ} 14\right)$ dedicado a la «igualdad y no discriminación», se señala en la parte pertinente:

«(...) La noción de igualdad se desprende directamente de la unidad de naturaleza del género humano y es inseparable de la dignidad esencial de la persona, frente a la cual es incompatible toda situación que, por considerar superior a un determinado grupo, conduzca a tratarlo con privilegio; o que, a la inversa, por considerarlo inferior, lo trate con hostilidad o de cualquier forma lo discrimine del goce de derechos que si se reconocen a quienes no se consideran incursos en tal situación de inferioridad (...)».

\section{MODELOS DE REPARACIÓN INTEGRAL}

Es necesario que los operadores de justicia sobre quienes recae la responsabilidad de verificar si existe una vulneración de derechos, dicten las medidas de reparación adecuadas. Para ello, los jueces pueden seguir modelos de reparación reconocidos en las sentencias de la CIDH o desarrolladas por la Corte Constitucional Ecuatoriana especialmente en lo relacionada a la reparación económica o indemnización. Existe un modelo de reparación individual y otro colectivo.

Los dos modelos de reparación pueden aplicarse en un mismo caso, sin la necesidad de que el uno discrimine al otro. Incluso las medidas de reparación pueden variar de un caso a otro, por ello es necesaria la evaluación del daño ocasionado para proponer un tipo de reparación especifico en el que pueden concurrir la restitución, indemnización, rehabilitación, medidas de satisfacción y garantías de no repetición.

Aunque como lo hemos mencionado, las reparaciones no se garantizan únicamente con la expedición en una sentencia. Incluso el sistema 
interamericano presenta algunas deficiencias. Por ejemplo, en el caso Suarez Rosero v. Ecuador la Corte Interamericana emitió su sentencia en el año 1999 y recién se hizo efectiva en el año 2011 (Benavides \& Escudero, 2013).

En Ecuador, la sentencia condenatoria en materia penal que se encuentre ejecutoriada, con la vigencia del Código Orgánico Integral Penal, debe contener la reparación integral sea material, inmaterial o ambas para la víctima del delito, y de no ser cumplida por el sentenciado, la victima debe recurrir al Código Orgánico General de Procesos (COGEP), como norma supletoria del referido cuerpo legal para su ejecución, con la finalidad de hacer cumplir la obligación, conforme a las reglas establecidas en el Libro V de Ejecución del COGEP.

\section{IV.1. Reparación individual}

La combinación adecuada de reparaciones individuales y colectivas permite «promover la justicia, remediando las violaciones manifiestas de las normas internacionales de derechos humano» (Resolución 60/147 de 16 de diciembre de 2005, Art.15). Las reparaciones deben corresponder a todos los daños sufridos por las víctimas, de manera proporcional, adeudada y oportuna, procurando en lo posible, borrar los efectos de las violaciones producidas.

Por ello es necesario otorgar reparaciones proporcionales, adecuadas y oportunas a todas las víctimas. La jurisprudencia reciente ha logrado ya grandes avances, reconociendo de manera explícita las modalidades de rehabilitación, indemnización y rehabilitación. Empero, las reparaciones exigidas deben, además, satisfacer a las víctimas y garantizar la no repetición de los hechos.

Todas las modalidades de reparación indicadas, requieren en algún grado, la participación activa del Estado. Si el Estado no interviene en las múltiples reparaciones que son necesarias para satisfacer los derechos de las víctimas a través de reformas institucionales, actos simbólicos y aportes pecuniarios, sería difícil dar cumplimiento a la reparación, por lo tanto, una de las formas de hacerlo, es a través de los operadores de justicia (jueces).

Las reparaciones individuales deben reflejar el daño experimentado por los individuos en particular y se dirigen a sus necesidades personales. Se debe considerar, no sólo la gravedad de los daños, sino también las particularidades que éstos presentan respecto de cada grupo que conforma el universo de víctimas.

Así, para establecer un modelo de reparación individual, es menester singularizar las necesidades de las víctimas individuales, a partir de un enfoque de derechos y de los principios aplicables a las reparaciones. Dentro 
de estos principios, toman especial relevancia las medidas afirmativas que deben tomarse en beneficio de las víctimas más vulnerables que requieren atención urgente.

Las modalidades de reparación que se han desarrollado a nivel de normas internacionales de los derechos humanos y de normas jurisprudenciales, y que pueden contribuir a sobrellevar y superar cuando son posible los daños, son la indemnización, la restitución y la rehabilitación. Tales modalidades, no tienen solamente una dimensión individual, en la medida que sus beneficios, especialmente cuando se trata de la restitución y de la rehabilitación, pueden llegar a la comunidad como un todo, y al individuo que desarrolla su acción social en ésta.

Debe señalarse finalmente, que pese a las ventajas que conllevan las reparaciones individuales, éstas son limitadas porque son selectivas, y pueden conducir a la estigmatización de los beneficiarios y a generar tensiones dentro de las comunidades. En todo caso, el reconocimiento del daño individual exige reparaciones individuales, siempre que éstas no modifiquen negativamente el entorno social de la víctima.

\section{a) Restitución}

El objetivo de la restitución es devolver a la víctima a la situación en que se encontraba antes del cometimiento del crimen, es decir, restaura la vida de un individuo incluyendo su retorno a la familia, a su domicilio y empleo anterior.

El primer objetivo de las medidas de reparación debe ser la restauración, toda vez que el retorno a la familia, casa o anterior empleo, coadyuvaría a cesar las violaciones de derechos (Resolución 60/147 de 16 de diciembre de 2005. Art.19) Sólo en pocos casos, es posible generar una forma de restauración, en uno o más de los ámbitos que caracterizaban la situación de una víctima, pero que no se identifican con tal situación como un todo. Así, por ejemplo, favorecer el reintegro al empleo, o el regreso a la familia, permite que una persona regrese a vivenciar una dimensión de su situación anterior, pero esto no borra los efectos que éstas generan en su comportamiento familiar y laboral.

No obstante, la Corte Constitucional para el período de transición ha mencionado en un caso concreto que:

«es materialmente imposible devolver al estado original la situación del accionante, pues dicha posibilidad no depende de la mera voluntad o querer humano o de esta Corte, sino de las limitaciones fácticas del mundo real. Por lo expuesto, esta Corte tiene la obligación de dar una solución que trate de reconstruir de manera lógica e integral la situación del perjudicado» (Sentencia 002-12/SIS-CC). 
Por ello cuando resulte imposible la restitución es necesario optar por las otras medidas de reparación existentes.

\section{b) Indemnización monetaria}

La indemnización es una forma de alivio económico que debe abarcar todos los daños, pérdidas o perjuicios causados incluyendo el daño físico, psicológico y material (CIDH, De la Masacre de Las Dos Erres v. Guatemala, § 226). Debe ser considerada cuando (i) el daño económico es suficientemente cuantificable, (ii) debe ser apropiada y proporcional según la gravedad del crimen y circunstancias del hecho, y (iii) existir fondos disponibles.

Para dar una justa indemnización a las víctimas afectadas (Convención Americana de Derechos Humanos, art. 64) se debe tener en cuenta la magnitud del daño material como moral. Definiendo que el daño es la denotación de dolor, lesiones y perjuicio, considerando que debe ser personal, y no necesariamente directo.

La indemnización debe considerar (i) el daño físico, (ii) el daño moral y no material como resultado del sufrimiento físico, mental y emocional, (iii) daños materiales que incluyen la pérdida de ingresos, y (iv) gastos realizados por las víctimas.

El daño no material abarca los sufrimientos y aflicciones causadas a las víctimas directas (CIDH, Acosta Calderón v. Ecuador, § 158) y a sus familiares (CIDH, Las Palmeras v. Colombia, § 55). Este daño es propio de la naturaleza humana al momento en que las víctimas experimentaron sufrimientos, angustia, terror, impotencia e inseguridad (CIDH, Loayza Tamayo v. Perú, § 158).

En cambio, el daño moral es la violación de un derecho personalísimo que puede ser reclamado por la víctima, incluye perjuicios a la honra, el sufrimiento y dolores derivados de los crímenes cometidos. Es asociado con el padecimiento de ansiedad, humillación, inculcación de sentimientos de inferioridad, frustración e impotencia (CIDH, Blake v. Guatemala, § 20).

También, se considera el daño moral y no material a las víctimas indirectas ante el desconocimiento del paradero de su familiar y la ineficacia de las autoridades del Estado de emprender una investigación diligente de lo sucedido (CIDH, Las Hermanas Serrano Cruz v. El Salvador, § 159).

Los daños materiales causados a las víctimas hacen referencia a la pérdida de ingresos, salarios o sueldos (CIDH, Castillo Páez v. Perú, § 77), desde el momento de su detención. Por lo que se debe considerar las condiciones de las que hubieran disfrutado las víctimas si no se hubieran 
cometido los crímenes, y el tiempo en que se han visto impedidos de trabajar (Nash, 2009, p. 43).

Aunque la Corte Constitucional se ha manifestado en la siguiente forma reconociendo que la indemnización debe ser un valor adicional a lo que se adeuda como objeto mismo de un proceso judicial:

«(...) la remisión a los preindicados trámites (...) no procede cuando se trata de pago de remuneraciones ordenado por la sentencia como parle de la medida reparatoria destinada a restablecer la situación de la víctima al estado preexistente a la vulneración de derecho, por cuanto, en este caso: i) No se trata de una indemnización de daños y perjuicios propiamente dicha (...) ii) Porque, objetivamente, no existe un monto de dinero a determinar, pues el monto de la remuneración del afectado, es un valor conocido que ya está determinado con anterioridad y absoluta precisión en la operación económica de la persona o entidad, pública o privada, que debe cumplir lo resucito en sentencia (...)» (Sentencia 02414-SIS-CC).

Se debe considerar todos aquellos gastos en que haya incurrido cada una de las víctimas con el objeto de reparar el daño sufrido causado por los crímenes. Por lo que es pertinente fijar una cantidad por compensación debido a los daños no materiales, de manera equitativa (CIDH, Masacres de Ituango v. Colombia, § 387).

En referencia a los gastos o daño emergente, se tomará en cuenta lo siguiente: (i) las gestiones realizadas de las víctimas indirectas en búsqueda de sus familiares y (ii) tratamientos médicos y psicológicos como resultado del daño sufrido por los crímenes.

Para la Corte Constitucional para el período de transición:

«Dicha reparación, de carácter material, puede y debe ser analizada en relación a las particularidades de cada situación; se requiere una individualización pormenorizada de los elementos fácticos y jurídicos que rodearon al caso para encontrar un justo equilibrio entre las aspiraciones del accionante y la parte demandada» (Sentencia 013-09-SIS-CC).

Esto debido a que en algunos casos la indemnización se la dicta cuando las medias de restitución no son adecuadas por los límites de los hechos facticos y de la vida real. Incluso la declaración del monto de indemnización, para la Corte Constitucional constituye un acto de ejecución de la sentencia que debe ventilarse, ya sea en la vía contenciosa administrativa cuando sea en contra del Estado, y en la vía civil cuando sea en contra de un particular (Corte Constitucional, Sentencia 004-13-SAN-CC). 


\section{c) Rehabilitación}

Los graves crímenes que afectaron a las víctimas y sus familiares, conlleva a una serie de traumas, trastornos, enfermedades, complicaciones físicas y psíquicos, violando los derechos integridad y libertad personal. Así, por ejemplo, la prestación de servicios médicos y asistencia psicológica (CIDH, Cantoral Benavides v. Perú § 143).

Cuando se decida que la reparación se logra a través de la rehabilitación es necesario la intervención del Estado. Revierte especial relevancia esta medida toda vez que, puede confundirse con la anterior concepción del derecho penal según la cual se reparaba a la víctima, rehabilitando al delincuente. En este caso, la mirada recae únicamente en la victima que, en la mayoría de la producción jurídica de las cortes penales internacionales, son la principal población afectada y necesita rehabilitación.

\section{IV.2. Reparación colectiva}

Las reparaciones colectivas benefician a grupos específicos de personas y a la comunidad en general, y su objetivo es restablecer la solidaridad social e incluir medidas dirigidas a la reconciliación de la comunidad con el acusado.

En la jurisprudencia de tribunales regionales las modalidades de reparación colectiva, van dirigidas al Estado. Esto porque los beneficiaros se entiende que es la sociedad en su conjunto. Despierta especial relevancia en la jurisprudencia las reparaciones sobre las comunidades indígenas a través del reconocimiento de su titularidad como sujetos de derechos colectivos como la propiedad comunal, entre otros.

La reparación colectiva considera las siguientes formas de reparación: (i) Medidas de Satisfacción y (ii) Garantías de no Repetición. Generalmente corresponde a medidas tomadas por el Estado, en tanto que representan actos simbólicos para las víctimas, y en algunos casos cambios en la normativa vigente.

\section{a) Medidas de satisfacción}

Son medidas de reparación no pecuniaria, destinadas a restablecer la dignidad y dignificar la memoria de las víctimas y sus familiares. Son

medidas que entregan reparación a la víctima de forma simbólica o representativa, teniendo un impacto en la comunidad y en el entorno social al interior del Estado (CIDH, Acosta Calderón v. Ecuador, § 163).

Las medidas de satisfacción buscan: (i) reconocer la dignidad de las víctimas, (ii) ayudar a reorientar su vida (ONU, Principio 22) y (iii) trasmitir 
un mensaje de reprobación oficial de los graves crímenes cometidos (CIDH, De la Cruz Flores v. Perú, § 155).

Entre medidas de satisfacción, entre otras, tenemos las siguientes: (i) determinación y reconocimiento de responsabilidad, (ii) disculpas públicas, (iii) publicidad, (iv) conmemoración y (v) búsqueda de personas desaparecidas (CIDH, Caballero Delgado y Santana v. Colombia § 52).

El acto público de reconocimiento de responsabilidad está orientado a dignificar a las víctimas promoviendo un reconocimiento público de responsabilidad por parte de quien ha ocasionado directamente los crímenes y no haberlas protegido (CIDH, Castañeda Gutman v. México § 239) El reconocimiento de responsabilidad y una ratificación de voluntad de que no vuelvan a ocurrir este tipo de hechos.

Para la disculpa pública se debe tener en cuenta las opiniones de cada una de las víctimas sobre la consideración de las disculpas, considerando que quizá algunas víctimas se sientan más cómodas sin tales disculpas, al menos si esta procede de forma directa.

La publicidad de la decisión de la Corte tiene como objetivo la publicación de la sentencia. Se debe publicar en un diario Oficial de amplia circulación nacional, en un sitio web oficial o por medios electrónicos de difusión y se lo realizará por una sola vez (CIDH, Bámaca Velásquez v. Guatemala, § 84).

Los homenajes o actos conmemorativos constituyen medidas de satisfacción de las víctimas que rescatan su recuerdo y memoria, sobre todo en casos de graves violaciones de derechos humanos. Esta medida es adecuada para reparar el daño sufrido por los familiares (CIDH, Ticona Estrada y otros v. Bolivia, § 165).

En el caso del Ecuador, en materia penal también se encuentran las medidas de satisfacción como mecanismos de reparación integral:

«Las medidas de satisfacción o simbólicas: se refieren a la declaración de la decisión judicial de reparar la dignidad, la reputación, la disculpa y el reconocimiento público de los hechos y de las responsabilidades, las conmemoraciones y los homenajes a las víctimas, la enseñanza y la difusión de la verdad histórica (...)» (Código Orgánico Integral Penal, Art. 78.4).

\section{b) Garantías de no repetición}

Las garantías trascienden la condición individual de las víctimas, para centrarse en las causas sociales, legales y políticas, que crearon una situación de graves violaciones a los derechos de las mismas (Herencia, 390) Se debe tener en cuenta dos requerimientos, (i) la supresión de normas y prácticas de cualquier naturaleza que impliquen violación a los derechos humanos, y (ii) 
la expedición de normas y el desarrollo de prácticas conducentes a la efectiva observancia de dichos derechos (CIDH, Castillo Petruzzi v. Perú $§ 207)$.

Las garantías de no repetición se pueden dividir en dos grupos: (i) medidas de capacitación y formación sobre derechos humanos y (ii) adopción de medidas en el derecho interno (CIDH, Caracazo v. Venezuela, $\S 112$ ). Estas últimas tienen especial relevancia en el derecho internacional de derechos humanos, debido a que las Cortes obligan a los Estados a través de sus sentencias, no solo a adecuar su derecho interno a los instrumentos internacionales de protección de los derechos, sino que obligan también a las autoridades a aplicar el principio de convencionalidad en sus sentencias, es decir ver que su contenido se apegue al contendido de los instrumentos internacionales.

Estas garantías de no repetición constituyen el mejor desarrollo jurisprudencial de la CIDH, toda vez que, son la garantía de que los hechos no se vuelvan a repetir y para ello es necesario realizar trasformaciones dentro del ordenamiento jurídico como modificar tipos penales. Por ello, la responsabilidad de reparar a través de este tipo de reparación corresponde al Estado a través de sus instituciones y agentes.

Siempre las medidas han sido dictadas por la CIDH, pero el desafío en Ecuador recae en la Corte Constitucional, la encarga de vigilar e interpretar el contenido de la Constitución. La Corte Constitucional puede dictar las medidas de no repetición toda vez que le faculta la Ley Orgánica de Garantías Jurisdiccionales y Control Constitucional, y a través ello podría exigir que las instituciones del Estado tomen medidas adecuadas para que los hechos no vuelvan a ocurrir.

No obstante, la jurisprudencia de la Corte Constitucional ha avanzado en lo que se refiere a la indemnización como medida de reparación, y existe un escaso desarrollo de las modalidades de reparación colectiva de los daños ocasionados.

En el Ecuador, en materia penal también se encuentra dispuesta la garantía de no repetición como mecanismo de reparación integral:

«(...) Las garantías de no repetición: se orientan a la prevención de infracciones penales y a la creación de condiciones suficientes para evitar la repetición de las mismas.

Se identifican con la adopción de las medidas necesarias para evitar que las víctimas sean afectadas con la comisión de nuevos delitos del mismo género (...)» (Código Orgánico Integral Penal, Art. 78.5). 


\section{CONCLUSIONES}

1. La reparación integral es un derecho de las víctimas reconocido en el derecho internacional de los derechos humanos, y en el derecho penal internacional. Por ello, se reconocen varios principios aplicables al momento de dictar una reparación, los mismos que han sido desarrollados por la jurisprudencia e instrumentos en el derecho internacional de los derechos humanos.

2. Entre los principios de aplicación de la reparación integral encontramos la necesidad de establecer estándares de dignidad, no discriminación y no estigmatización al momento de dictar las medidas de reparación. Asimismo, el reconocimiento en procesos judiciales de las víctimas directas e indirectas.

3. Existen dos modalidades para reparar integralmente a las víctimas, una que es individual y otra que es colectiva. Entre la modalidad de reparación individual encontramos la restitución, la rehabilitación y la indemnización; mientras que, la colectiva incluye las medidas de satisfacción y las garantías de no repetición.

4. Todas ellas han sido desarrolladas por la jurisprudencia de la CIDH, y han servido como base para establecer mecanismos de reparación integral en el derecho interno de los Estados.

\section{REFERENCIAS}

Arroyo, Lenin. "Victimología. Una visión desde el saber penal- criminológico a la afirmación científica de la imputación objetiva".

Benavides, J. \& Escudero, J. (2013). Manual de justicia constitucional ecuatoriana. Quito: Corte Constitucional del Ecuador, 2013. (Cuadernos de trabajo, 4).

CIDH (2019). Cuadernillo de Jurisprudencia, 14.

CIDH, Acosta Calderón v. Ecuador, Sentencia de 24-VI-2005

CIDH, Bámaca Velasquez v. Guatemala, Sentencia de 22-II-2002.

CIDH, Blake v. Guatemala, Sentencia de 22-I-1999,

CIDH, Cantoral Benavides v. Perú, Sentencia de 3-XII-2001.

CIDH, Caracazo v. Venezuela, Sentencia de 29-VIII-2002.

CIDH, Castillo Páez v. Perú, Sentencia 27-XI- 1998

CIDH, Castillo Petruzzi v. Perú, Sentencia de 30-V-1999

CIDH, De la Masacre de Las Dos Erres v. Guatemala, sentencia de 24-XI- 2009. 
CIDH, Las Hermanas Serrano Cruz v. El Salvador, Sentencia de 1-III-2005.

CIDH, Las Niñas Yean y Bosico v. República Dominicana, Sentencia de 8-IX-2005.

CIDH, Las Palmeras v. Colombia, Sentencia de 26 de-XI- de 2002.

CIDH, Loayza Tamayo v. Perú, Sentencia de 27-XI- 1998.

CIDH, Masacres de Ituango v. Colombia, sentencia de 1-VII-2006.

CIDH, Suarez Rosero v. Ecuador, Sentencia de 20-I-1999.

Corte Constitucional del Ecuador para el período de transición. Sentencia 002-12/SIS-CC, caso 0021-09-IS, de (05-I-2012).

Corte Constitucional del Ecuador. Sentencia 004-13-SAN-CC, caso 0015-10-AN, de (13IV-2010).

Corte Constitucional del Ecuador. Sentencia 009-14-SIS-CC, Caso N ${ }^{\circ}$ 0081-11-IS, de (29I-2014).

Corte Constitucional del Ecuador. Sentencia 031- 15-SIS-CC, Caso Nº031-10-IS de (29IV-2015).

Ecuador, Constitución de la República del Ecuador, Registro Oficial 449, 20-X-2008.

Ecuador, Constitución Política de la República del Ecuador, Registro Oficial 1, 11 de-VIIIde 1998.

Ecuador, Ley Orgánica de Garantías Jurisdiccionales y Control Constitucional, Registro Oficial suplemento 52, 22-X-2009.

Nash Rojas, C. (2009). Las reparaciones ante la Corte Interamericana de Derechos Humanos (1988-2007), 2a ed. Santiago de Chile: Universidad de Chile.

Neuman, Elías. "Victimología. El Rol de la Victima en los delitos Convencionales y no Convencionales".

ONU (16 de diciembre de 2005). Resolución 60/147. Principios y directrices básicos sobre el derecho de las víctimas de violaciones manifiestas de las normas internacionales de derechos humanos y de violaciones graves del derecho internacional humanitario a interponer recursos y obtener reparaciones. 